\title{
RECICLAGEM DE EFLUENTES NO PROCESSO DE TINGIMENTO SINTÉTICO EM UMA INDÚSTRIA TÊXTIL: ESTUDO DE CASO
}

Joel Dias da Silva ${ }^{1}$

Michelle de Andrade ${ }^{2}$

\begin{abstract}
RESUMO
Este estudo foi desenvolvido com objetivo de demonstrar a viabilidade da reciclagem dos efluentes tratados para o processo de tingimento sintético sem alterar a qualidade do produto final, tornando assim uma ferramenta de gestão e desenvolvimento sustentável para a empresa. Para isso, realizou-se a avaliação do histórico de parâmetros físico-químicos, o percentual de reciclagem de efluentes/dia em um ano assim como os respectivos resultados de testes de sublimação do fio que garantem a qualidade do tingimento. Realizado esse levantamento pode-se definir o percentual de efluentes/dia a ser reciclado no processo de tingimento, do qual em média constatou-se que $30 \%$ dos efluentes gerados na produção, após passar por um tratamento via físico-químico, retornou ao processo. Para se garantir a qualidade do produto final, comparou-se um processo padrão com um processo que reciclou $30 \%$ dos efluentes tratados, por meio da realização de testes de sublimação do fio e resultados de análises dos efluentes. Os resultados foram satisfatórios, não demonstrando nenhuma alteração na qualidade do tingimento.
\end{abstract}

Palavras chaves: Reciclagem de Efluentes. Tingimento Sintético. Qualidade.

'Doutor, e-mail: joeldias@sc.senai.br

Especialista, e-mail: michelle.ambiental@gmail.com 


\section{INTRODUÇÃO}

Não é recente a preocupação de governos, companhias e diversos segmentos da sociedade com as heranças residuais (efeitos nocivos) resultantes do uso das inovações tecnológicas, principalmente pela indústria, cujos impactos têm sido cada vez mais percebidos no meio ambiente, no mundo do trabalho e, consequentemente, na vida das populações (GAVIÃO; SIQUEIRA; SPERS; 2006).

Diante deste cenário, o setor industrial têxtil tem sofrido nos últimos anos uma série de transformações importantes, motivadas pela busca da qualidade e preço para os seus produtos em função de um mercado extremamente competitivo, mas ao mesmo tempo, de forma sustentável, adotando práticas como o uso racional/eficiente da água, tratamento adequado dos resíduos, efluentes e subprodutos do processo (FERREIRA; SPANHOL e KELLER, 2009).

O processo produtivo têxtil é caracterizado por um elevado consumo de água, gerando um grande volume de efluentes líquidos, além de ter uma concentração elevada de matéria orgânica (MELO 2005; SCHNEIDERS, 2011). São necessários aproximadamente $80 \mathrm{~L}$ de água para produzir $1 \mathrm{~kg}$ de tecido. Contudo, há referência a valores da ordem de $150 \mathrm{~L}$, sendo que $80 \%$ deste volume são descartados como efluente e apenas $12 \%$ do total compõem as perdas por evaporação, como os mencionados por Immich, (2006). Segundo Hassemer (2006), na produção de tecido de algodão, por exemplo, o consumo

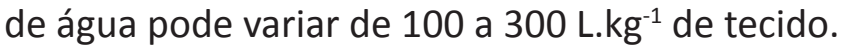

Schneiders (2011) salienta ainda que as inúmeras operações necessárias para dar ao tecido o máximo de propriedades geram em cada etapa diferentes despejos. A característica destes efluentes depende diretamente do tipo de substrato têxtil que está sendo processado, dos corantes, surfactantes e produtos químicos diversos utilizados e do tipo de equipamento. Portanto, pode-se observar uma gama enorme de variações das características quantitativas e qualitativas dos efluentes. (MIO, CAMPOS, 1998; LACERDA, 2004).

Diante desse quadro, acrescenta-se ainda que, as regulamentações ambientais ficaram mais restritivas com o passar dos anos, através da implementação de uma série de medidas como a cobrança pelo uso da água e pelo descarte de efluentes, padrões de emissão no corpo receptor mais restritivos, bem como crescentes aumentos nos custos de tratamento e disposição final de resíduos e subprodutos do tratamento de efluentes. Tais fatores, segundo Peixoto (2011) fazem com que as tecnologias de produção mais limpa e reuso da água industrial cresçam como alternativas ambientalmente viáveis. 
Quanto à questão da qualidade da água utilizada no processo têxtil, esta por sua vez possui limites de tolerância e restrições que variam conforme o processo produtivo, porém, de acordo com Litte (1975) nem todos os processos precisam ter a mesma exigência de qualidade. Assim, o reuso de água poderá ser direto ou indireto, decorrente de ações planejadas ou não (CENTRO INTERNACIONAL DE REFERÊNCIA EM REUSO DE ÁGUA, FUNDAÇÃO CENTRO TECNOLÓGICO DE HIDRÁULICA; DTC ENGENHARIA, [20--?]):

a) reuso indireto não planejado: ocorre quando a água, utilizada em alguma atividade humana, é descarregada no meio ambiente e novamente utilizada a jusante em sua forma diluída, de maneira não intencional, e não controlada;

b) reuso indireto planejado: ocorre quando os efluentes, depois de tratados, são descarregados de forma planejada nos corpos d'água superficiais ou subterrâneos, para o uso a jusante na forma diluída e de maneira controlada;

c) reuso direto planejado de água: ocorre quando os efluentes, após tratamento, são encaminhados diretamente de seu ponto de descarga ate o local de reuso, não são descarregados no meio ambiente. É o caso da maior ocorrência, destinando-se a indústria ou irrigação;

d) reciclagem de água: é o reuso interno da água, antes de sua descarga em um sistema geral de tratamento ou outro local de disposição, para servir como fonte suplementar de abastecimento do uso original. É o caso particular do reuso direto.

Pode se destacar ainda que o reuso reduz a demanda sobre os mananciais devido à substituição da água potável por uma água de qualidade inferior, para fins menos nobres. Assim, mais que reutilizar, a racionalização do uso da água na indústria têxtil é possível ser conseguida com a modernização dos equipamentos e incremento tecnológico nos processos e produtos, visando uma menor utilização desse recurso natural tão escasso. Para minimizar o consumo de água é necessário o monitoramento dos desperdícios diários no processo produtivo, do mesmo modo que se procede com outros insumos como o ar comprimido, energia térmica ou energia elétrica, visando à contenção de despesas na empresa (TWADOKUS, 2004).

Neste estudo pretende-se demonstrar os resultados da análise de reciclagem de efluentes tratados buscando demonstrar a viabilidade do mesmo para o processo de tingimento sintético, tendo sido conduzido em uma tinturaria de fios sintéticos. Esta linha de fios sintéticos vem crescendo cada vez mais no mercado produtivo devido à falta de algodão nos últimos anos. Uns dos grandes interesses da empresa pela reciclagem dos efluentes, além da preservação ambiental, é a localização em que esta se encontra - uma região quase que estritamente residencial e sem nenhum curso d'água para uma possível captação para abastecimento - uma vez que, a água utilizada para todos os processos produtivos é aquela proveniente do sistema público de abastecimento de água da cidade. 


\section{A INDÚSTRIA TÊXTIL E A RECICLAGEM DE EFLUENTES}

O complexo industrial têxtil do Estado de Santa Catarina está localizado principalmente no Vale do Itajaí, Blumenau. De acordo com o recorte regional definido pelo Serviço Brasileiro de Apoio às Micro e Pequenas Empresas de Santa Catarina (SEBRAE/SC), a maior concentração destas empresas está localizada nas coordenadorias regionais do Vale do Itajaí, Foz do Itajaí e Norte. Em 2008, estas três regionais somavam 78,3\% das empresas e 68,8\% dos empregos do setor catarinense (SERVIÇO BRASILEIRO DE APOIO ÀS MICRO E PEQUENAS EMPRESAS, 2010).

A indústria têxtil, especialmente o setor de beneficiamento, é responsável pela poluição, principalmente dos corpos de água, das regiões em que atua. $O$ beneficiamento têxtil consiste em um conjunto de processos aplicados aos materiais têxteis objetivando transformá-los, a partir dos estados crus, em artigos brancos, tingidos, estampados e acabados. Este engloba as etapas de desengomagem, alvejamento, a lavagem de tecidos, mercenarização, tingimento, a estamparia e o acabamento de tecidos. Nestas etapas tem-se a geração de efluentes líquidos, gerando cerca de 400L para produzir 1 $\mathrm{kg}$ de tecido, sem falar nos produtos químicos durante os processos têxteis a úmido (FORGIARINI, 2006).

Com o aparecimento da fibra de acetato, foram desenvolvidos corantes com baixa solubilidade em água e com maior solubilidade na fibra. Estes corantes na realidade ficam dispersos no banho de tingimento e seu diâmetro de partícula gira em torno de 0,5 a 2,0 microns e por isso foram chamados de "corantes dispersos" (DOLZAN, 2004).

Na década de 50 a fibra poliéster (PES), foi a classe de corantes que melhor se adaptou ao tingimento, onde são realizados sob pressão e ou acima de 100 ㄷ com o auxilio de um carrier (agente dilatador da fibra), em desuso por questões ecológicas e econômicas. A temperatura ideal é de 130 a 135 ㄷ․ Nestas condições a energia calorífica transmitida ao corante disperso transforma-se em energia cinética (movimento) e as suas moléculas dispõem de maior potencia para atravessar a barreira molecular e se difundir dentro da fibra (DOLZAN, 2004).

Os corantes dispersos estão divididos em três classes, a saber, moléculas grandes, médias e pequenas, o tamanho desta é determinante para a solidez à sublimação. A sublimação é propriedade que tem o corante pela ação do calor passar do estado sólido para gasoso e é uma característica dos corantes dispersos (DOLZAN, 2004).

Com as limitações de reservas de água doce no planeta, o aumento da demanda de água para atender, principalmente, o consumo humano, agrícola e industrial, a prioridade de utilização dos recursos hídricos disponíveis para abastecimento público e as restrições que vêm sendo impostas em relação ao lançamento de efluentes no meio ambiente, torna necessária a adoção de estratégias que visem racionalizar a utilização dos recursos 
hídricos e mitigar os impactos negativos relativos à geração de efluentes pelas indústrias (CENTRO INTERNACIONAL DE REFERÊNCIA EM REUSO DE ÁGUA, FUNDAÇÃO CENTRO TECNOLÓGICO DE HIDRÁULICA; DTC ENGENHARIA, [20--?]).

Para melhor garantir os recursos hídricos, bem como promover seu uso de forma racional, a legislação estabeleceu a outorga e a cobrança pelo uso da água. Surgiu assim o conceito do usuário-pagador, que está associado à figura do poluidor-pagador. Ou seja, a indústria deverá pagar tanto pela captação de água como pelo lançamento de seus efluentes.

Do ponto de vista ambiental, a indústria têxtil é considerada uma atividade potencialmente poluidora e, como tal, esta sujeita as pressões do poder público, da comunidade e de clientes. Como resposta, a empresa precisa ter um posicionamento seguro com relação aos seus impactos ambientais. Ações como melhorias nos processos produtivos e redução dos desperdícios são cada vez mais valorizadas (REÚSO..., 2008).

\section{METODOLOGIA}

O principal procedimento deste trabalho foi a comparação entre um processo padrão que utiliza $100 \%$ de água fornecida pelo abastecimento público, com um processo reutilizando efluente tratado. Nesse sentido, buscou-se traçar um cenário de avaliação a partir da caracterização da empresa, com um levantamento do histórico de reuso de efluentes na mesma, para fins de comparação com os resultados de parâmetros físicoquímicos da mesma. Testes de sublimação a solidez do fio, que determina a qualidade do tingimento, também foram efetuados, uma vez que, estes ajudarão a determinar o percentual de reuso de efluente diário.

Para tal, coletaram-se amostras de ambos os processos e estas foram encaminhados ao Laboratório de Análises de Águas e Efluentes (LANAE) do Serviço Nacional de Aprendizagem Industrial (SENAI) Blumenau, para que, posteriormente, os resultados pudessem ser discutidos em relação à qualidade do produto final.

A determinação da qualidade do produto (fio tinto) foi avaliada através de testes de sublimação, cujo procedimento é descrito na Associação Brasileira de Normas Técnicas (ABNT) NBR 10.188/1988 que determina a solidez da cor à fricção, através da ação do ferro de passar a quente por 15 segundos sobre um pano branco por cima da amostra de tingimento. Características como a tonalidade da cor, corantes utilizados em cada cor, concentração de produtos auxiliares, e tolerância da água para utilização nos processos têxteis, também foram avaliados. A verificação da tonalidade da cor foi realizada na empresa através de controles internos por cartelas onde são armazenadas amostras da cor tingida, conforme representado na figura 1. 


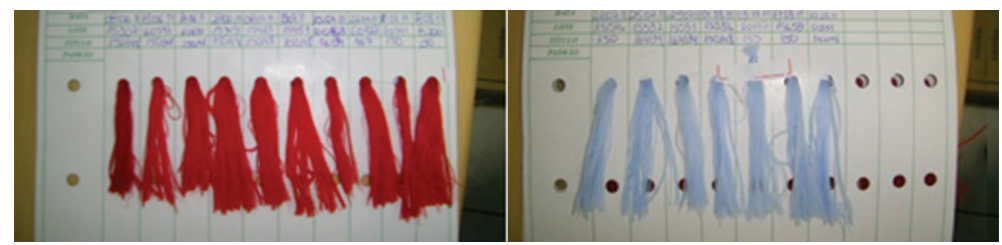

Fonte: Empresa do estudo de caso (2012)

Os parâmetros analisados para as comparações dos processos de tingimento foram determinados com base nos estudos de Little (1975), onde os limites de tolerância que garantem a qualidade do tingimento foram destacados. Efetuou-se também a avaliação do parâmetro DQO - Demanda Química de Oxigênio, uma vez que, o composto tem características de recalcitrância, podendo apresentar alguma alteração na qualidade do fio. O procedimento experimental foi realizado com coleta de amostras em processos de tingimento de cor clara e cor escura, em fio poliéster classificada como 75/34, ou seja, são 34 filamentos que compõe o título no 75. Conforme tabela 1 apresenta-se a descrição dos corantes utilizados em cada cor.

Tabela 1: Receitas de tingimento

\begin{tabular}{l|l|l|l}
\hline \multirow{2}{*}{ CódIGO DA COR } & $\begin{array}{l}\text { TONALIDADE } \\
\text { DA COR }\end{array}$ & $\begin{array}{l}\text { CORANTES } \\
\text { UTILIZADOS }\end{array}$ & $\begin{array}{l}\text { CONCENTRAÇÃO } \\
\text { DE CORANTE \% }\end{array}$ \\
\hline \multirow{2}{*}{8062} & \multirow{2}{*}{ Escura } & Castanho SER & $0,54 \%$ \\
\cline { 3 - 4 } & & Rubi S2G & $0,61 \%$ \\
\cline { 2 - 4 } & Rosa BEL & $0,357 \%$ \\
\hline \multirow{2}{*}{2062} & \multirow{2}{*}{ Clara } & Azul EFBL & $0,035 \%$ \\
\cline { 3 - 4 } & & Rubi S2G & $0,0008 \%$ \\
\hline
\end{tabular}

Fonte: Dos autores

Os produtos auxiliares utilizados em cada processo de tingimento foram: igualizante, dispersante, redutiva e amaciante com as respectivas concentrações nos processos de tingimento conforme apresentados na tabela 2. 
Tabela 2: Concentração de produtos auxiliares

\begin{tabular}{l|l|l|l}
\hline \multirow{2}{*}{ Código da cor } & Tonalidade & $\begin{array}{l}\text { Produtos auxiliares } \\
\text { utilizados }\end{array}$ & Concentração \% \\
\hline \multirow{2}{*}{8062} & \multirow{2}{*}{ Escura } & SERA GAL PLP & 1 gL-1 \\
\cline { 3 - 4 } & Clara & LEVACID & 0,2 gL-1 \\
\hline 2062 & \multicolumn{2}{|c}{ SERA GAL PLP } & 1 gL1 \\
\hline \multicolumn{2}{r}{ Fonte: Dos autores }
\end{tabular}

Foram comparadas as amostras coletadas no início do processo de tingimento padrão com os limites de tolerância da água para utilização em processo têxtil conforme referência bibliográfica. Parâmetros de qualidade da água foram também selecionados para a determinação de uma possível influência na qualidade final do produto têxtil, bem como sua tolerância em $\mathrm{mgL}^{-1}$ para cada parâmetro, levando-se em consideração que nem todos os processos precisam ter a mesma exigência de qualidade.

Tabela 3: Tolerância da água para utilização nos processos têxteis

\begin{tabular}{l|l}
\hline Qualidade ou Substância & Tolerância (mgL-1) \\
\hline Turbidez & $<5$ \\
\hline Cor & $<5$ (unidade PtCo) \\
\hline $\mathrm{pH}$ & entre 7 - 9 \\
\hline Dureza & $<70$ como CaCO3 \\
\hline Óleos e Graxas & $<250$ \\
\hline Ferro & $<0,3$ \\
\hline \multicolumn{2}{|c}{ Fonte: Little (1975) }
\end{tabular}

\section{RESULTADOS OBTIDOS}

\subsection{Histórico}

Na tabela 4, relaciona-se o total de efluentes tratados por mês com o total de efluentes retornado para o processo de tingimento, juntamente com a média dos resultados de parâmetros como ph e cor respectiva do mês e o histórico de resultados de controles da qualidade do fio. 
Tabela 4: Relação do histórico de dados

\begin{tabular}{|c|c|c|c|c|c|c|}
\hline \multirow[t]{2}{*}{ Mês/2010 } & \multicolumn{2}{|c|}{$\begin{array}{l}\text { Média dos } \\
\text { parâmetros } \\
\text { físico-químicos }\end{array}$} & \multirow[t]{2}{*}{$\begin{array}{l}\text { Resultados } \\
\text { de Testes de } \\
\text { Sublimação }\end{array}$} & \multirow[t]{2}{*}{$\begin{array}{l}\text { Tratado } \\
\mathrm{m}^{3} / \mathrm{mês}\end{array}$} & \multirow[t]{2}{*}{$\begin{array}{l}\text { Retornado } \\
\mathrm{m}^{3} / \mathrm{mês}\end{array}$} & \multirow[t]{2}{*}{$\begin{array}{l}\text { Percentual de } \\
\text { reciclagem \% }\end{array}$} \\
\hline & Cor & $\mathrm{pH}$ & & & & \\
\hline Janeiro & - & 6,9 & Ok & 1.069 & 327,00 & 30,59 \\
\hline Fevereiro & - & 7,0 & Ok & 1.701 & 839,50 & 49,35 \\
\hline Março & 140,0 & 7,1 & Ok & 1.563 & 408,00 & 26,10 \\
\hline Abril & 131,0 & 7,5 & Ok & 1.821 & 678,00 & 37,23 \\
\hline Maio & 34,8 & 7,1 & Ok & 1.476 & 529,00 & 35,84 \\
\hline Junho & 144,0 & 7,1 & Ok & 1.795 & 628,00 & 34,99 \\
\hline Julho & 252,0 & 7,3 & Ok & 2.121 & 667,00 & 31,45 \\
\hline Agosto & 278,0 & 7,3 & Ok & 1.724 & 383,00 & 22,22 \\
\hline Setembro & 194,0 & 6,9 & Ok & 1.503 & 427,00 & 28,41 \\
\hline Outubro & 227,0 & 7,0 & Ok & 1.657 & 720,00 & 43,45 \\
\hline Novembro & 215,0 & 6,9 & Ok & 1.715 & 461,00 & 26,88 \\
\hline Dezembro & 150,0 & 7,1 & Ok & 495 & 111,00 & 22,42 \\
\hline
\end{tabular}

\subsection{Resultados analíticos}

Os resultados apresentados na tabela 5 relacionam os dois processos de tingimento. A questão da qualidade da água utilizada no processo têxtil, este por sua vez possui limites de tolerância e restrições que variam conforme processo produtivo. Para Little (1975) nem todos os processos precisam ter a mesma exigência de qualidade. Conforme descrito pelo autor, analisando os resultados da amostra de entrada do processo de tingimento padrão, pode-se observar que os parâmetros entraram no processo de tingimento com níveis de tolerância aceitáveis conforme referencia bibliografia. 
Tabela 5: Parâmetros - Processo de tingimento com reciclagem de efluente

\begin{tabular}{|c|c|c|c|c|c|c|}
\hline \multirow{3}{*}{ Parâmetro } & \multirow{3}{*}{$\begin{array}{c}\text { Entrada } \\
\text { (reciclado) }\end{array}$} & \multirow{3}{*}{$\begin{array}{l}\text { Entrada } \\
\text { (padrão) }\end{array}$} & \multicolumn{2}{|l|}{ Cor Clara } & \multicolumn{2}{|l|}{ Cor Escura } \\
\hline & & & $\begin{array}{l}\text { Processo } 30 \% \\
\text { reciclado }\end{array}$ & $\begin{array}{l}\text { Processo } \\
\text { Padrão }\end{array}$ & $\begin{array}{l}\text { Processo } 30 \% \\
\text { reciclado }\end{array}$ & $\begin{array}{l}\text { Processo } \\
\text { Padrão }\end{array}$ \\
\hline & & & $\begin{array}{l}\text { Amostra de } \\
\text { Saída }\end{array}$ & $\begin{array}{l}\text { Amostra } \\
\text { de Saída }\end{array}$ & $\begin{array}{l}\text { Amostra de } \\
\text { Saída }\end{array}$ & $\begin{array}{l}\text { Amostra } \\
\text { de Saída }\end{array}$ \\
\hline $\mathrm{pH}$ & 7,02 & 6,90 & 6,98 & 6,78 & 8,99 & 8,00 \\
\hline Cor & 126,58 & 5 & 673 & 458 & 1510,0 & 890 \\
\hline Turbidez & 2,34 & 1,39 & 19,0 & 466 & 23,04 & 24,2 \\
\hline Dureza & 29,7 & 22,57 & 97,03 & 76,83 & 74,06 & 47,52 \\
\hline DQO & 985,00 & 40,0 & 1663,0 & 164,0 & 1245 & 1219 \\
\hline $\begin{array}{l}\text { Óleos e } \\
\text { Graxas }\end{array}$ & 4,25 & 2,8 & 34,75 & 173,5 & 11 & 16,25 \\
\hline Ferro & $<0,1$ & $<0,1$ & 0,11 & 0,14 & 0,4 & 0,38 \\
\hline $\begin{array}{l}\text { Teste de } \\
\text { Solidez }\end{array}$ & & - & & & & \\
\hline
\end{tabular}

Fonte: Empresa do estudo de caso (2012)

A partir dos testes de qualidade efetuados, verificou-se que, os resultados foram elevados para cada tonalidade de cor, seja esta escura ou clara. Diante disso, verifica-se a possibilidade de existir um ciclo controlado de reciclagem contínua de efluentes para o processo de tingimento, bastando apenas o controle mais restrito desses parâmetros que garantirão a qualidade do tingimento. Estudos recentes comprovam que o número de ciclos de reutilização da mesma água para tingimento chega a um ponto em que os parâmetros se estabilizam e havendo nenhuma interferência no processo de tingimento. Após passar por um processo de tratamento físico-químico e na diluição com água de abastecimento publico esta poderá apresentar-se novamente com qualidade o suficiente para retornar ao processo de tingimento.

No Brasil, de acordo com Resende (2012), não há leis ou resoluções que determinem a prática de reuso na indústria, contudo, existe a obrigatoriedade de tratamento antes do descarte, prevista na Resolução 430/2011 do Conselho Nacional do Meio Ambiente (CONAMA), que estabelece os parâmetros de qualidade para lançamento do efluente em corpos receptores. 
Há também a Lei Ambiental 9.605/1998 que dispõe sobre as sanções penais e administrativas aos responsáveis por atividades prejudiciais ao meio ambiente. A iminente escassez de recurso hídrico e a adoção da cobrança pelo uso da água descrita na Lei 9.433/1997 - Politica Nacional de Recursos Hídricos, no entanto, tem estimulado a prática de reciclagem de água para usos não potáveis e em processos industriais.

Os resultados obtidos no processo de tingimento onde se reciclou $30 \%$ de efluente tratado pode-se observar que os parâmetros de entrada estão entrando no processo de tingimento com resultados muito acima da tolerância para qualidade da água, porém os testes comprovam a qualidade do fio tinto.

A análise tecnológica de alternativas de tratamento de efluentes tem o objetivo de prognosticar, para uma dada situação real, qual ou quais das alternativas teriam um melhor desempenho quando definitivamente implantadas no local determinado. Assim, ela pode condicionar o sucesso do projeto, da operação e da manutenção de uma futura estação de tratamento de efluentes (CORDEIRO NETTO et al., 2000).

Nagel e Mayer (1999) apud Leoneti (2009) defendem que não deveria existir uma lacuna entre a variável ambiental e a variável econômica. Argumentam que soluções ambientalmente corretas geralmente levam às econômicas, uma vez que a redução de consumo de matéria-prima e de energia, reciclagem ou qualquer outra atitude sustentável afetarão ao mesmo tempo tanto a econômica quanto ambiental. Porém, é necessário estar atento à legislação pertinente como também qualquer outra certificação que se deve atender.

A indústria têxtil apresenta elevado potencial para aplicação de técnicas que viabilizem o reuso de água, dada a grande quantidade demanda desse insumo na produção, e as diversas possibilidades de recondicionamento de seus efluentes, tratados por processos convencionais ou não. Geralmente as indústrias têxteis conduzem o tratamento de seus efluentes até o nível biológico, utilizando sistema de lodos ativados, capaz de adequá-los às condições legais de lançamento. $O$ tratamento complementar vem como opção de polimento do efluente, inclusive visando a seu reuso (RIBEIRO, 2009).

Por fim salienta-se que os processos de tingimento foram $100 \%$ produzidos com fios sintéticos poliéster $75 / 34$, e que os testes de sublimação a solidez do fio foram realizados no laboratório próprio da empresa com resultados positivos, ou seja, nenhum dos processos realizado houve migração de corante para a malha. Este teste é baseado no procedimento descrito na ABNT NBR 10.188/1988 do qual determina a solidez da cor a fricção. 


\section{CONSIDERAÇÕES FINAIS}

A conclusão deste estudo vem ao encontro de soluções técnicas para o controle de qualidade da água para tingimentos sintéticos. Foi possível demonstrar a viabilidade da reciclagem de efluentes tratados com parâmetros acima do limite de tolerância da qualidade da água para processos têxteis e que ainda sim asseguram a qualidade do tingimento sintético, em fio poliéster.

As análises realizadas no processo padrão foram de extrema importância para ter uma referência de qualidade no tingimento, assim como a obtenção dos dados de parâmetros da água utilizada antes do processo e após o processo de tingimento. Além dos testes de sublimação a solidez da cor da qual não apresentou nenhuma alteração, demonstrando confiabilidade no processo de tingimento padrão e assim tomá-la como referencia nas análises realizadas no processo de tingimento que reutilizou $30 \%$ de efluente tratado. Comparado os processos, foi possível alcançar o objetivo deste estudo, através da realização de testes de sublimação do fio e resultados de análises, além da determinação da quantidade de efluente reciclado.

A empresa com essa ferramenta de controle e minimização dos recursos hídricos também pode ter o beneficio econômico, reduzindo em até $55 \%$ em relação ao custo que seria pago ao Serviço Autônomo Municipal de Água da cidade, se não houvesse a reciclagem dos efluentes.

Por fim, recomenda-se a continuidade deste estudo para a busca de melhorias no processo para se alcançar um maior percentual de reutilização dos efluentes e também para se obtiver dados importantes quanto aos resultados de parâmetros da água com concentrações maiores de efluente reutilizado no processo e principalmente na obtenção para a expansão de dados sobre este assunto pouco estudado porem muito aplicativo, a reutilização de efluentes tratados em processo de tingimento sintético. 


\title{
RECYCLING IN THE PROCESS OF DYEING WASTEWATER IN A SYNTHETIC TEXTILE INDUSTRY: A CASE STUDY
}

\begin{abstract}
This study was conducted with the objective of demonstrating the feasibility of recycling of effluents treated for synthetic dyeing process without changing the quality of the final product, thus making it a tool of management and sustainable development for the company. To achieve this goal, the evaluation of the history of physical and chemical parameters, the percentage of recycling of effluent/day in a year as well as the results of tests of sublimation of the wire to ensure the quality of dyeing were conducted. After conducting this survey, the percentage of effluent / day to be recycled in the dyeing process can be defined, of which it was found that on average $30 \%$ of the wastewater generated in the production, after undergoing a physical-chemical treatment, returned to the process. To ensure the quality of the final product a standard process was compared with a process that recycled $30 \%$ of the treated effluent through sublimation testing of the wire and effluent analysis results. The results were satisfactory, not showing any changes in the quality of dyeing.
\end{abstract}

Keywords: Wastewater Recycling, Synthetic Dyeing, Quality. 


\section{REFERÊNCIAS}

ASSOCIAÇÃO BRASILEIRA DE NORMAS TÉCNICAS. ABNT NBR 10.188/1988:

determinação da solidez da cor ao ferro de passar a quente. Rio de Janeiro, 1988.

BYTYN, Wilfried. REÚSO em uma indústria textil. Revista HYDRO, São Paulo, ano 3, n. 25. p.7-10, nov. 2008.

CENTRO INTERNACIONAL DE REFERÊNCIA EM REUSO DE ÁGUA, FUNDAÇÃO CENTRO TECNOLÓGICO DE HIDRÁULICA; DTC ENGENHARIA. Conservação e Reuso de Água: manual de orientação para o setor industrial, volume 1. São Paulo: FIESP, [20--?].

CORDEIRO NETTO et. al. Uma metodologia para análise tecnológica de sistemas com reatores biológicos anaeróbios para tratamento de águas residuárias municipais. In: Anais CONGRESSO INTERAMERICANO DE ENGENHARIA SANITÁRIA E AMBIENTAL, 27.,2000, Porto Alegre. Anais... Porto Alegre, AIDIS, 2000.

DOLZAN, N. Tingimento de fibras sintéticas com corantes dispersos. 2004. Dissertação (Mestrado em Engenharia Química)-Universidade Federal de Santa Catarina, Florianópolis, 2004.

FERREIRA, Denize Demarche Minatti; SPANHOL, Greicy Kelli; KELLER, Jacqueline. Gestão do processo têxtil : contribuições à sustentabilidade dos Recursos Hídricos. In: CONGRESSO NACIONAL DE EXCELÊNCIA EM GESTÃO: GESTÃO DO CONHECIMENTO PARA A SUSTENTABILIDADE, 5., 2009, Niterói, RJ. Anais... Niterói, RJ: [s.n.], 2009.

FORGIARINI, E. Degradação de corantes e efluentes têxteis pela enzima Horseradish Peroxidase (HRP). 2006. Dissertação (Mestrado em Engenharia Química)-Universidade Federal de Santa Catarina, Florianópolis, 2006.

GAVIÃO, P. D.; SIQUEIRA, E. S.; SPERS, E. E. A Responsabilidade Sócioambiental e a Tomada de Decisão do Gestor do Setor Têxtil. In: ENEGEP - ENCONTRO NACIONAL DE ENGENHARIA DE PRODUÇÃO, 26., 2006, Fortaleza, CE. Anais... Fortaleza, CE: [s.n], 2006.

HASSEMER, M.E.N. Oxidação fotoquímica - Uv/ $\mathrm{H}_{2} \mathrm{O}_{2}$ - para degradação de poluentes em efluentes da indústria têxtil. 2006. 175 f. Tese (Doutorado em Engenharia Ambiental)-Universidade Federal de Santa Catarina, Florianópolis, 2006. 
IMMICH, A. P. S. Remoção de corantes de efluentes têxteis utilizando folhas de Azadirachta indica como adsorvente. 2006. 119 f. Dissertação (Mestrado em Engenharia Química)-Universidade Federal de Santa Catarina, Florianópolis, 2006.

LACERDA, J. P. Estudo do impacto ambiental nos cursos d' água causado pelo lançamento de efluentes de indústrias do município de Itabirito/MG. 2004. 108 f. Dissertação (Mestrado em Engenharia Ambiental)-Universidade Federal de Ouro Preto, Ouro Preto, MG, 2004.

LEONETI, A. B. Avaliação de modelo de tomada de decisão para escolha de sistema de tratamento de esgoto sanitário. 2009. 154 f. Dissertação (Mestrado em Administração de Organizações)- Faculdade de Economia, Administração e Contabilidade de Ribeirão Preto- FEARP, Universidade de São Paulo, USP, Ribeirão Preto,SP 2009.

LITTLE, A. H., Water Supplies and the Treatment and Disposal of Effluents, The Textile institute Manchester, n. 2, 1975.

MELO, A. R. Otimização do reuso de água em lavadores contínuos da indústria têxtil. 2005. 219 f. Dissertação (Mestrado em Engenharia Química) - Universidade Federal de Santa Catarina, Florianópolis, 2005.

MIO, G. P.; CAMPOS, J. R. Proposição de método para avaliação da remoção de cor em efluentes líquidos de indústria têxteis. In: CONGRESSO INTERAMERICANO DE INGENIERÍA SANITARIA Y AMBIENTAL, 5., 1998, Lima. Anais... Lima, AIDIS, 1998. p. 1-10.

PEIXOTO, T. C. L. C.. Reuso de água: comparação entre os métodos dfa, programação linear e programação não linear. 2011. Dissertação (Mestrado em Ciência da Engenharia Química)-Universidade Federal do Rio de Janeiro, Rio de Janeiro, 2011.

RIBEIRO, M. C. M. Avaliação da possibilidade de reúso de efluentes têxteis após tratamento complementar por processos oxidativos avançados. 2009. $78 \mathrm{f}$.

Dissertação (Saneamento, Meio Ambiente e Recursos Hídricos) - Universidade Federal de Minas Gerais, Belo Horizonte, 2009.

RESENDE, Letícia Passos. Reuso na indústria têxtil e lavanderias. Revista Hydro, São Paulo, ano 6, n.66, p.14-19, abr. 2012. Disponível em: <http://sindlav.com.br/wpcontent/uploads/2012/05/H66-Especial.pdf> Acesso em: 09 ago. 2012. 
SCHNEIDERS, D. Potencial de geração de biogás no tratamento de efluente e lodo têxtil em reator anaeróbio de fluxo ascendente e manta de lodo (UASB). 2011.

Projeto de Qualificação (Mestrado em Engenharia Ambiental)-Universidade Regional de Blumenau, Blumenau, 2011.

SERVIÇO BRASILEIRO DE APOIO ÀS MICRO E PEQUENAS EMPRESAS. Santa Catarina em Números: têxtil e confeç̧ão. [S.I.], 2010.

TWARDOKUS, Rolf Guenter. Reuso de Água no processo de Tingimento da Indústria Têxtil. 2004. Dissertação (Mestrado em Engenharia Química)-Universidade Federal de Santa Catarina, Florianópolis, 2004.

\section{SOBRE OS AUTORES}

\begin{tabular}{||l||l||}
\hline Joel Dias da Silva & $\begin{array}{l}\text { Engenheiro Sanitarista (1999) pela UFMT, com Mestrado (2002) e Doutorado } \\
\text { (2007) em Engenharia Ambiental, ambos pela UFSC. Atualmente é bolsista } \\
\text { do Programa MEC/CAPES PNPD, realizando o seu Pós-Doutorado em } \\
\text { Engenharia Ambiental na FURB - Universidade Regional de Blumenau junto } \\
\text { ao Programa de Pós-Graduação em Engenharia Ambiental. Atua como } \\
\text { Instrutor Nível V no Núcleo Ambiental do SENAl Blumenau, e também } \\
\text { como professor colaborador e orientador do Mestrado Profissionalizante } \\
\text { em Engenharia Ambiental com Ênfase em Gestão Ambiental, parceria entre } \\
\text { a UFSC e o ICE (Instituto de Competências Empresariais) representando a } \\
\text { FIAT Automóveis. Possui experiência na grande área da Engenharia Sanitária } \\
\text { e Ambiental, com ênfase em resíduos sólidos urbanos e industriais, assim } \\
\text { também como em efluentes industriais e tecnologias de tratamento. }\end{array}$ \\
\hline
\end{tabular}

\begin{tabular}{|c||l||}
\hline $\begin{array}{l}\text { Mecialista em Gerenciamento de Águas e Efluentes - SENAI, 2012. } \\
\text { Graduada como Tecnologia em Gestão Ambiental - SENAI, } 2009 \text { e técnica } \\
\text { em Meio Ambiente, SENAI 2007. Atualmente concluindo curso técnico em } \\
\text { Segurança do Trabalho - CEDUP, 2013. Experiência com sistemas de gestão } \\
\text { ambiental e gestão de pessoas. Atuou como técnica em meio ambiente em } \\
\text { estações de tratamento de efluente, Coordenação de equipes, treinamentos } \\
\text { e implantação de PGRS e na fiscalização em obra terceirizada para Transpetro } \\
\text { S.A. }\end{array}$ \\
\hline
\end{tabular}

